\title{
Benefits of threshold strategies and age-selective harvesting in a fluctuating fish stock of Norwegian spring spawning herring Clupea harengus
}

\author{
Katja Enberg* \\ Integrative Ecology Unit, Department of Biological and Environmental Sciences, Division of Ecology and Evolutionary \\ Biology, PO Box 65 (Viikinkaari 1), 00014 University of Helsinki, Finland
}

Present address: Department of Mathematics and Statistics, PO Box 68 (Gustaf Hällströmin Katu 2b), 00014 University of Helsinki, Finland

\begin{abstract}
The current state of the world's fisheries resources requires further investigation into the means and methods for sustainable use of fish stocks. In this study, I assess the performance of different harvesting strategies on a population model developed for Norwegian spring spawning herring Clupea harengus, a stock historically known as one of the largest and most valuable fish stocks in the world. This stock is further characterized by strong long-term fluctuations in stock size, which considerably complicate successful population management. The results support the use of threshold strategies, where harvesting is only allowed if the population size of the target population is above a predetermined threshold. Threshold strategies are beneficial for maintaining spawning biomass, yield, and prevention of population collapse. The downside of a threshold approach is the fisheries moratoria associated with low stock size. To overcome this, I introduce a precautionary strategy including 2 thresholds for reducing the likelihood and length of moratoria, such that if the population size decreases below an upper threshold, the harvest ratio is decreased in order to achieve fast recovery to the target population size. I also test the effect of changing the timing of fish entering the harvestable stock by means of age-selective harvesting. I show that allowing reproduction, preferably more than once, before the fish become vulnerable to harvesting increases the spawning biomass and yield, and decreases the variability in yield and the risk of stock collapse.
\end{abstract}

KEY WORDS: Harvesting strategy $\cdot$ Threshold $\cdot$ Norwegian spring spawning herring $\cdot$ Age-selective harvesting $\cdot$ Precautionary strategy

\section{INTRODUCTION}

The world fisheries resources are being depleted at a considerable rate (FAO 2004, Hutchings \& Reynolds 2004). As overfishing is a major threat to fish stocks worldwide (Ludwig et al. 1993, Casey \& Myers 1998), it is necessary to look for more sustainable ways of utilizing marine resources. Often, ceasing harvesting does not guarantee a recovery (Rose et al. 2000). Moreover, the importance of taking into account the natural variation in environmental conditions affecting the renewal and survival of fish resources cannot be overemphasized (Hofmann \& Powell 1998, Arnott \&
Ruxton 2002). Even though it has been claimed that the ultimate fate of all populations is extinction, at least in the light of history (Jablonski 1986), exploitation can severely hasten the process of declining marine resources by pushing the populations to such low levels that environmental variation or demographic stochasticity will have fatal effects (Pauly et al. 2002). Globally, $28 \%$ of marine fish stocks are overexploited or depleted, and $50 \%$ are fully exploited; thus, management of fish resources worldwide has hardly proved itself successful (FAO 2004).

Threshold harvesting strategies, where harvesting is only allowed if the size of the target population is 
above a predetermined threshold, are supposed to perform very well especially when population size or environment is highly variable (Quinn et al. 1990, Lande et al. 1994, 1995, 1997, Mace 1994, Sæther et al. 1996, Engen et al. 1997, Ludwig 1998). In particular, the inferiority of the proportional harvest strategy, where a predetermined proportion of the population is removed regardless of the population size before harvesting, has been highlighted. In general, threshold strategies are argued to perform well as precautionary strategies, minimizing the extinction risk while optimizing yield. Moreover, threshold strategies supposedly perform well in varying circumstances including critical depensation, catastrophes (stock collapses), and with a strongly fluctuating recruitment rate (Ludwig 1998).

Random variations in the environment are likely to affect the dynamics of populations, through changes in individual life histories (Benton et al. 2002). In population modelling, environmental stochasticity has traditionally been assumed to have a neutral autocorrelation structure, i.e. the fluctuations are totally random. However, environmental variables and population fluctuations are often autocorrelated; as an example, marine environmental variables (especially temperature) fluctuate slowly. This means that their dynamics are dominated by low-frequency variation and are positively autocorrelated (Steele 1985, Halley 1996). Importantly, populations characterized by autocorrelated dynamics are prone to population crashes, as the variance in the stock abundance increases with the length of time over which the variance is estimated (e.g. Halley \& Kunin 1999). Exploitation further increases the variability in population abundance (Beddington \& May 1977, May et al. 1978), and at low population sizes vulnerability to chance events increases (May 1974).

The Norwegian spring spawning herring Clupea harengus is considered to be one of the largest and most valuable fish stocks in the world (Bjørndal et al. 1997). Harvestable biomass is believed to have been $10 \times 10^{6} \mathrm{t}$ in the early 1960s (Bjørndal et al. 2000). These fish feed on plankton in pelagic zones, with feeding confined to a few months in spring and summer. The herring stock is characterized by fluctuating recruitment, which leads to strong long-term fluctuations in stock size (Toresen \& Østvedt 2000). The major driving force in population fluctuations is recruitment variability (Sæetre et al. 2002), and in herring both recruitment and spawning stock size are positively correlated with average winter temperature in the Kola section in the Barents Sea (Toresen \& Østvedt 2000). In addition, year-class strength and growth co-vary closely with temperature in Norwegian spring spawning herring and other species in the Norwegian and Barents seas (Loeng et al. 1995, Ottersen \& Loeng 2000). Time series analysis applied to the herring stock dynamics indicates that herring dynamics are intrinsically positively autocorrelated (Kaitala et al. 2003). The stock is further characterized by its highly migratory nature; juveniles commonly dwell in the Barents Sea, whereas mature fish undertake extensive feeding migrations after spawning off the Norwegian west coast. The Norwegian spring spawning herring stock experienced a major population crash in the 1960s, and the fishery was closed during the 1960s and 1970s. During the 1980s, only small catches were allowed. This stock has since recovered and is at present within safe biological limits with the spawning biomass fluctuating around $5 \times 10^{6} \mathrm{t}$ (ICES 2003).

The harvesting tactic currently employed for the Norwegian spring spawning herring stock is a total allowable catch (TAC) system. A long-term management plan has been agreed on for this fishery since 1999 between the European Union, the Faeroe Islands, Iceland, Norway and Russia. The management plan aims at preventing spawning stock biomass (SSB) falling below $2.5 \times 10^{6} \mathrm{t}$, and setting TACs consistent with producing a fishing mortality of less than $0.125 \mathrm{yr}^{-1}$. Provisions are also made to adjust the fishing mortality should the SSB fall below $5 \times 10^{6} \mathrm{t}$ (ICES 2003). TACs are based on biological information and guidelines from the International Council for the Exploration of the Seas (ICES) (Sandberg et al. 1998, ICES 2003). Three vessel types are used in Norwegian spring spawning herring fishery, including purse seine, trawlers, and coastal vessels (Bjørndal et al. 2000). Most of the herring is used for human consumption, yet 20 to $30 \%$ is used for fishmeal and oil (Bjørndal et al. 1997).

In this study, my aim is to explore the performance of different harvesting strategies, also taking into account the fluctuating nature of fish stocks. I use a population dynamics model developed for the Norwegian spring spawning herring. For harvesting strategies, I analyze 3 different and very basic options: (1) proportional harvesting, (2) threshold harvesting, and (3) proportional threshold harvesting. I also suggest 2 new precautionary modifications of these strategies that seem to be, on the basis of this study, more appropriate when harvesting highly fluctuating populations. In addition, since the model is an age-structured model, I modify these basic strategies taking into account the size (age) at first harvest, indicating the necessity, or possibility, of size-selective harvesting. I also investigate the interactions between harvest strategies and selection schemes that have not been addressed in previous studies. 


\section{MATERIALS AND METHODS}

Here, I present a model of herring stock dynamics based on parameter values estimated from the Norwegian spring spawning herring (Patterson 1998, see also Touzeau et al. 2000). Of the several alternative models analyzed by Patterson (1998), none performed superiorly compared to the others; thus, I have chosen to use an age-structured population model with a BevertonHolt recruitment function.

The age-structured population dynamics are defined as:

$$
N_{i, t}=N_{i-1, t-1} \mathrm{e}^{-m_{i-1} \varepsilon_{t}}
$$

where $N_{i, t}$ is the number of individuals in age-class $i$ in year $t, m_{i}$ is the instantaneous natural mortality at age $i$, and $\varepsilon_{t}$ is the environmental noise (see below). The population is divided into 17 age-classes, from 0 to 16 . For the initial abundances at $t=1$, I use data from the herring population averaged over years from 1993 to 1996 (Patterson 1998). Instantaneous natural mortality is very high for Age-classes 0 to $2(\mathrm{~m}=$ $0.9 \mathrm{yr}^{-1}$ ). For the adult part of the stock (age-classes >2), $m=0.15 \mathrm{yr}^{-1}$.

The population renewal process is subjected to environmental stochasticity, $\varepsilon$. $\varepsilon_{t}$ is taken after a first-order autoregressive process (Ripa \& Lundberg 1996):

$$
\varepsilon_{t}=\kappa \varepsilon_{t-1}+s_{t} \sqrt{1-\kappa^{2}}
$$

where $\kappa$ is the autocorrelation parameter. In this study, positively correlated noise was used since the factors affecting growth and survival (such as temperature, Loeng et al. 1995, Ottersen \& Loeng 2000) are positively autocorrelated; moreover, the herring population dynamics are intrinsically positively autocorrelated (Kaitala et al. 2003). The term $s$ is a normallydistributed, random variable with range $\left(1-w_{1} 1+w_{\text {, }}\right.$ where $w=0.2$ ); the square root term scales the variance of the generated time series so that its true variance is independent of $\kappa$ (Heino et al. 2000).

The stock-recruitment relationship is used to relate the number of recruits to the size of the spawning stock. Often, recruits are considered to be the juveniles entering the exploitation phase (i.e. stock), but in this model, they are regarded as larvae and metamorphosed individuals under Age 1 (i.e. Age 0). Consequently, the stock-recruitment relationship should be considered as a spawning function in this model. The recruitment, or spawning function used in this study is the Beverton-Holt function, which assumes food limitation and competition among the juveniles (Beverton \& Holt 1993).

In order to use the Beverton-Holt function, I first need to calculate SSB:

$$
\mathrm{SSB}=\sum_{i=0}^{i=16} M O_{i} S W_{i} N_{i, t}
$$

where $M O$ reflects the maturity ogive (Table 1), $S W$ stock weight (Table 1 ) and $N$ is the population abundance according to (Eq. 1). MO gives the mature proportion of age-classes. All individuals older than $7 \mathrm{yr}$ are considered to be reproductive, whereas none below Age-class 4 are mature.

The number of recruits $N_{0, t}$ (Age 0 individuals) at a given time is dependent on SSB as follows:

$$
N_{0, t}=\frac{a \mathrm{SSB}_{t}}{1+\mathrm{SSB}_{t} / b} \varepsilon_{t}
$$

where $a$ and $b$ are parameters estimated by Patterson (1998); $a=32.459 \mathrm{~kg}^{-1}, b=3044.867 \times 10^{6} \mathrm{~kg}$. SSB is calculated using Eq. (3), and $\varepsilon_{t}$ is calculated using Eq. (2) as described above.

In this paper, I contrasted 5 harvesting strategies, which are introduced in Table 2: (1) proportional harvesting, where a constant proportion of the total harvestable biomass is removed; (2) threshold harvesting, where a constant proportion of the total harvestable biomass will be removed when the spawning stock biomass is above a threshold; (3) proportional threshold harvesting, where a constant proportion of the excess in stock biomass above a threshold is removed; (4) precautionary threshold harvesting, where a constant proportion of the total harvestable biomass will be removed when the spawning stock biomass is above a threshold, the proportion depending on the stock size; and (5) precautionary proportional threshold harvesting, where a constant proportion of the excess in stock biomass above a threshold is removed, the proportion

Table 1. Maturity ogive (MO, \% of fish mature) and stock weight $\left(S W, \mathrm{~kg}\right.$ ind.$\left.^{-1}\right)$ estimated as mean values over data years 1993 to 1996 (Patterson 1998)

\begin{tabular}{|ccc|}
\hline Age class $i$ & $M O$ & $S W$ \\
\hline 0 & 0 & 0.0010 \\
1 & 0 & 0.0135 \\
2 & 0 & 0.0250 \\
3 & 0.0050 & 0.0745 \\
4 & 0.1550 & 0.1520 \\
5 & 0.7125 & 0.2343 \\
6 & 1 & 0.2995 \\
7 & 1 & 0.3468 \\
8 & 1 & 0.3598 \\
9 & 1 & 0.3825 \\
10 & 1 & 0.3875 \\
11 & 1 & 0.4017 \\
12 & 1 & 0.4037 \\
13 & 1 & 0.3945 \\
14 & 1 & 0.4053 \\
15 & 1 & 0.4033 \\
16 & 1 & 0.4138 \\
\hline
\end{tabular}


Table 2. Harvesting strategies, the conditions for harvesting, threshold values and the equations for calculating yield. $F=$ fishing mortality, $S=$ age-dependent selectivity parameter and $S W=$ stock weight. $\mathrm{SSB}_{t}$ is spawning stock biomass at year $t$ and $T_{\text {ref }}$ is the reference threshold for allowing population harvesting with full harvest ratio

\begin{tabular}{|c|c|c|c|c|}
\hline Strategy & Condition & Threshold $(T)$ & Equation for yield $\left(Y_{t}\right)$ & \\
\hline $\begin{array}{l}\text { Proportional } \\
\text { harvesting }\end{array}$ & None & None & $Y_{t}=\sum_{i=0}^{i=16} Y_{i, t}=\sum_{i=0}^{i=16} N_{i, t} S W_{i} F S_{i}=F \sum_{i=0}^{i=16} N_{i, t} S W_{i} S_{i}$ & (5) \\
\hline $\begin{array}{l}\text { Threshold } \\
\text { harvesting }\end{array}$ & $\begin{array}{l}\text { If } \mathrm{SSB}_{t}>T \text {, Eq. (5) applies, } \\
\text { otherwise } Y_{t}=0\end{array}$ & $2.5 \times 10^{6} \mathrm{t}$ & $Y_{t}=\sum_{i=0}^{i=16} Y_{i, t}=\sum_{i=0}^{i=16} N_{i, t} S W_{i} F S_{i}=F \sum_{i=0}^{i=16} N_{i, t} S W_{i} S_{i}$ & (5) \\
\hline $\begin{array}{l}\text { Proportional } \\
\text { threshold } \\
\text { harvesting }\end{array}$ & $\begin{array}{l}\text { If } \mathrm{SSB}_{t}>T, \text { Eq. (6) applies, } \\
\text { otherwise } Y_{t}=0\end{array}$ & $2.5 \times 10^{6} \mathrm{t}$ & $Y_{t}=\sum_{i=0}^{i=16} Y_{i, t}=\sum_{i=0}^{i=16}\left(N_{i, t} S W_{i}-T\right) F S_{i}$ & (6) \\
\hline $\begin{array}{l}\text { Precautionary } \\
\text { threshold }\end{array}$ & $\begin{array}{l}\text { If } \mathrm{SSB}_{t}>T_{\text {ref, }} \text { Eq. (5) applies } \\
\text { If } \mathrm{SSB}_{t}>T \text {, Eq. (7) applies }\end{array}$ & $T_{\text {ref }}=5 \times 10^{6} \mathrm{t}$ & $Y_{t}=\sum_{\substack{i=0 \\
i=16}}^{i=16} Y_{i, t}=\sum_{\substack{i=0 \\
i=16}}^{i=16} N_{i, t} S W_{i} F S_{i}=F \sum_{i=0}^{1=16} N_{i, t} S W_{i} S_{i}$ & $(5)$ \\
\hline harvesting & If $\mathrm{SSB}_{t}<T, Y_{t}=0$ & $T=2.5 \times 10^{6} \mathrm{t}$ & $Y_{t}=\sum_{i=0}^{I=16} Y_{i, t}=\sum_{i=0}^{I=16} N_{i, t} S W_{i}(F / 2) S_{i}=F / 2 \sum_{i=0}^{I=16} N_{i, t} S W_{i} S_{i}$ & $(7)$ \\
\hline $\begin{array}{l}\text { Precautionary } \\
\text { proportional }\end{array}$ & $\begin{array}{l}\text { If } \mathrm{SSB}_{t}>T_{\text {ref, }} \text { Eq. (6) applies } \\
\text { If } \mathrm{SSB}_{t}>T \text {, Eq. (8) applies }\end{array}$ & $T_{\text {ref }}=5 \times 10^{6} \mathrm{t}$ & $Y_{t}=\sum_{i=0}^{I=10} Y_{i, t}=\sum_{i=0}^{I=10}\left(N_{i, t} S W_{i}-T\right) F S_{i}$ & (6) \\
\hline $\begin{array}{l}\text { threshold } \\
\text { harvesting }\end{array}$ & If $\mathrm{SSB}_{t}<T, Y_{t}=0$ & $T=2.5 \times 10^{6} \mathrm{t}$ & $Y_{t}=\sum_{i=0}^{i=16} Y_{i, t}=\sum_{i=0}^{i=16}\left(N_{i, t} S W_{i}-T\right)(F / 2) S_{i}$ & (8) \\
\hline
\end{tabular}

being dependent on the stock size. The threshold $(T)$ was selected according to Bjørndal et al. 1997. Note that when the asymptotic harvest ratio equals 1 , proportional harvest strategy in this study is similar to the threshold strategy proposed by Ludwig (1998, 'optimal harvest strategy'), as all the biomass above the threshold is removed. Precautionary strategies were inspired by the fact that Norwegian spring spawning herring stock belongs to the few stocks in which management is based on a 'harvest control rule'; i.e., if SSB falls below $5 \times 10^{6} \mathrm{t}$, the fishing mortality rate should be adapted (based on scientific advice) so that SSB rapidly and safely recovers to a level above $5 \times 10^{6} \mathrm{t}$ (ICES 2003).

Further to this, I also explored the effect of ageselective harvesting within these 5 harvesting strategies. For simplicity, the selectivity was a 'knife-edge' selection such that $S_{i}$ only had values of 0 (not harvestable) and 1 (fully harvestable). First harvesting age had values of $3,5,7,9,11,13$, and 15 yr (in Figs. 1 to 3, only the first 4 cases are shown). In practice, ageselectivity would most likely need to be implemented as size-selectivity through gear restrictions. However, due to the correlation between age and size in fish populations, especially in the younger ages (e.g. Norwegian spring spawning herring, Patterson 1998), such selectivity should not be impracticable nor produce qualitatively different model results. Yet, it is worth mentioning that selection scenarios where first harvest age is higher than 11 are quite theoretical, as the size of individuals older than that differs only marginally (Patterson 1998). However, separation of herring belonging to age groups below 11 should be conceivable.
I ran the simulations for all harvest strategies and selectivity scenarios for 1000 time steps, 100 replicate runs, and for harvest ratios (or asymptotic harvest ratios for proportional threshold and precautionary proportional threshold strategies) ranging from 0 to 1. Mean values from these runs were used, except for the moratoria histogram, where results of a single run of 1000 time steps were used. From these simulations, I computed: (1) mean annual SSB and its standard deviation; (2) the mean annual yield in biomass, i.e. summed over age-classes, averaged over years and runs; (3) the coefficient of variation (CV) of yield (results shown in this paper are from the first 100 time steps, but using any other time span yields qualitatively identical results); (4) the risk of the stock going below the SSB threshold, hereafter SSB risk, (the proportion of time SSB spent below the critical threshold of $2.5 \times 10^{6} \mathrm{t}$ during the time series); (5) the probability of extinction (percentage of runs where population went extinct); (6) the time to extinction (how long did the population survive before extinction?); (7) the length and number of harvesting moratoria in threshold and proportional threshold strategies; (8) the yield:risk ratio for maximum yield and corresponding SSB risk (a variable describing the risk associated with maximum yield in each strategy); (9) the frequency of fisheries moratoria of different lengths in 1 run of 1000 time steps; and (10) the average number and length of harvesting moratoria in the threshold strategies. Criteria (4) to (10) have seldom been used in fisheries literature, even though they seem rather obvious criteria to use and are in line with FAO guidelines (FAO 1999). 


\section{RESULTS}

In the proportional harvest strategy, mean annual SSB was strongly dependent on the first harvest age (Fig. 1a). Increasing this age increases the mean annual SSB significantly, and a higher first harvest age also allows for a higher harvest ratio. Threshold and proportional threshold strategies produce rather similar mean annual SSB, yet using the proportional threshold strategy produced a higher SSB across different harvest ratios and first harvest ages, such that in proportional threshold harvesting, the SSB never goes below the lower threshold $(T)$, whereas in threshold harvesting this happens with first harvest ages 3 and 5 (Fig. 1b,c). Moreover, with first harvest age 9, the SSB in the proportional threshold harvesting strategy remains above the upper threshold ( $\left.T_{\text {ref }}\right)$ over different harvest ratios, but in threshold harvesting, higher harvest ratios cause the SSB to sink below $T_{\text {ref }}$ (Fig. 1b,c). Precautionary threshold and precautionary proportional threshold strategies both caused an increase in the mean annual SSB compared to threshold and proportional threshold strategies (data not shown).

Yield predictions were also dependent on the first harvest age applied, especially in the proportional
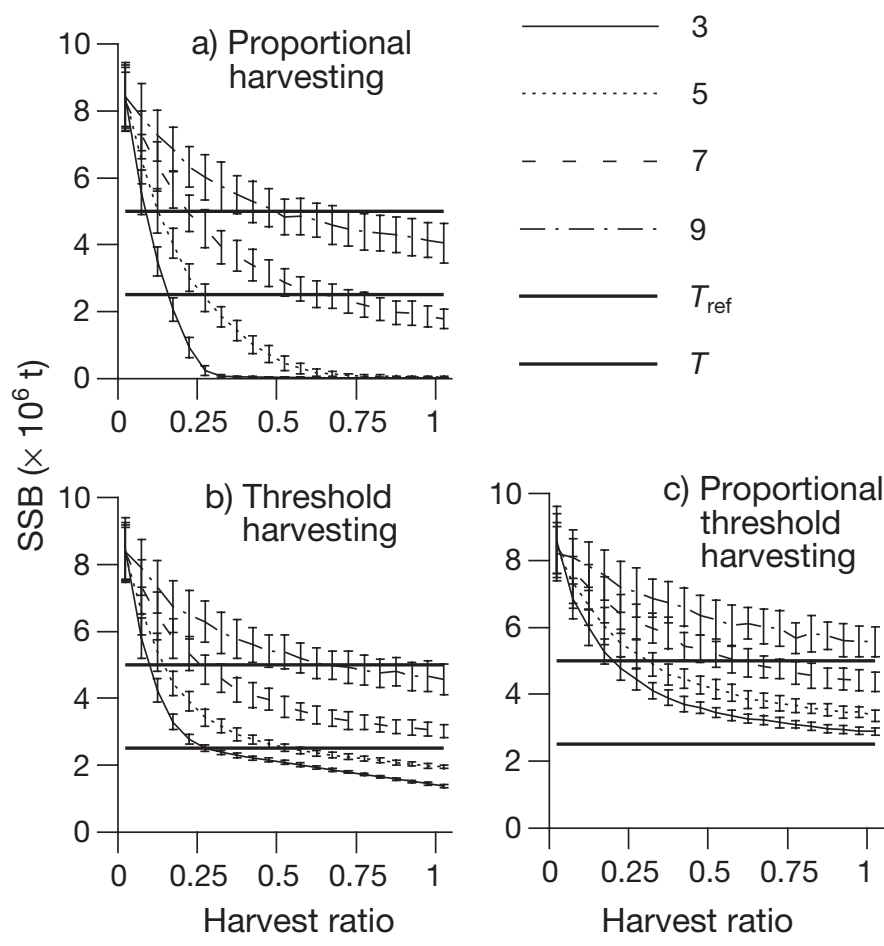

Fig. 1. Spawning stock biomass (SSB, in millions of metric tonnes with standard deviation) of Clupea harengus as a function of harvest ratio for different harvesting strategies and first harvest ages 3, 5, 7 and 9 yr. Horizontal lines indicate $T$ and $T_{\text {ref }}$ : lower and upper threshold, respectively
Proportional harvesting
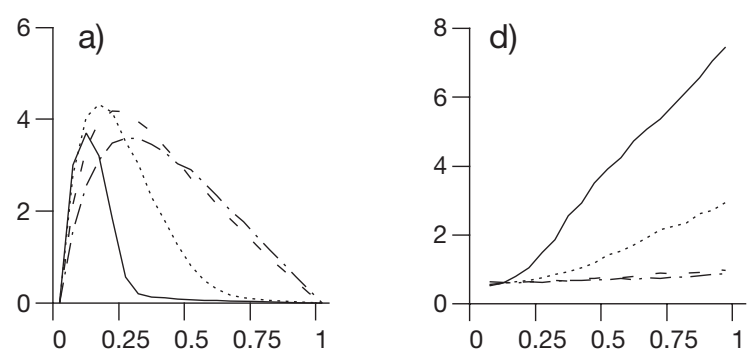

Threshold harvesting
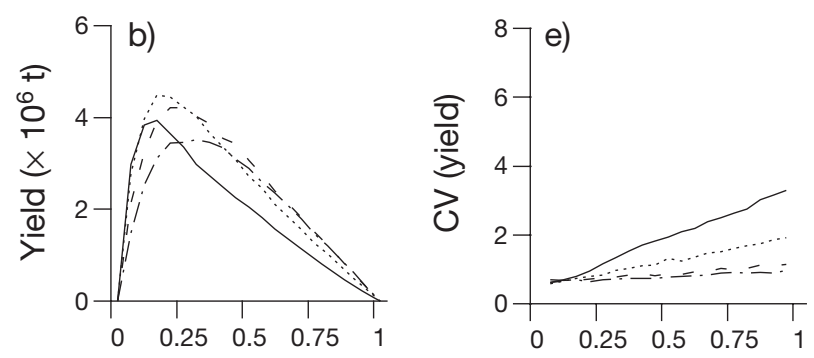

Proportional threshold harvesting
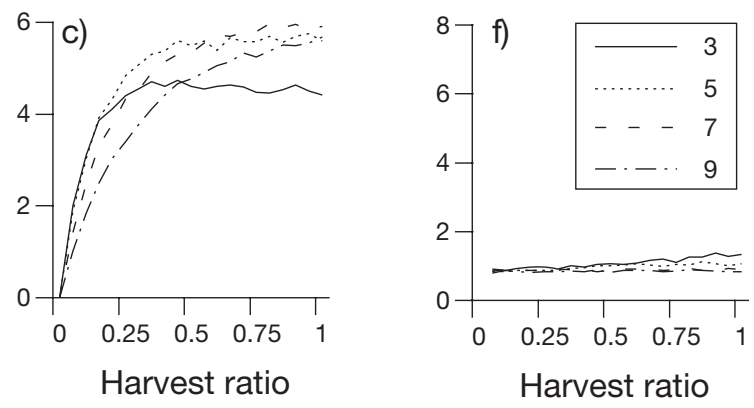

Fig. 2. (a-c) Mean annual yield of Clupea harengus in millions of metric tonnes and $(\mathrm{d}-\mathrm{f})$ coefficient of variation $(\mathrm{CV})$ of yield as a function of harvest ratio for different harvesting strategies. Different lines indicate first harvest ages (yr)

harvest strategy (Fig. 2a-c). Proportional and threshold strategies performed rather similarly in terms of mean annual yield, except that threshold harvesting allowed for a harvest ratio around $50 \%$ higher with a lower first harvested age class (Fig. 2a,b). However, when the first harvest age increased, the behavior of the proportional and threshold harvesting strategies became very similar. Moreover, maximum yields produced by the proportional and threshold harvesting strategies over different first harvest ages were surprisingly similar (Fig. 3a). However, differences arose in the CV of yield, the proportional harvesting strategy having nearly twice the $\mathrm{CV}$ of the threshold harvesting strategy (Fig. 2d,e). Increasing the first harvest age decreased the $\mathrm{CV}$ in both the proportional and threshold strategies. SSB risk was lower in the threshold harvesting strategy than in the proportional harvesting 


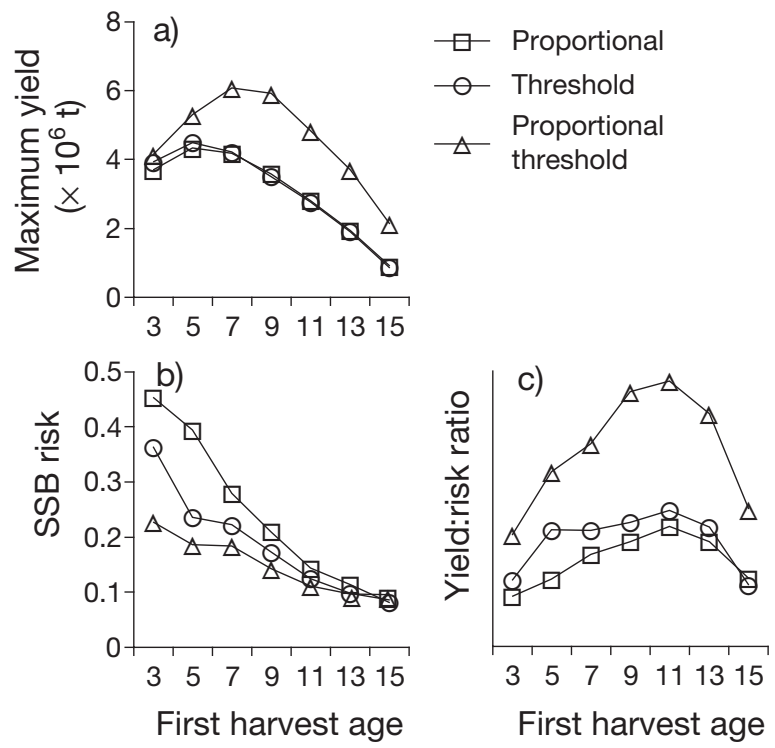

Fig. 3. (a) Maximum yield of Clupea harengus, (b) SSB risk corresponding to maximum yield, and (c) their ratio as a function of first harvest age in proportional, threshold, and proportional threshold harvesting strategies

strategy. Furthermore, at a higher harvest ratio, the proportional harvesting strategy produced a SSB risk equal to 1, with first harvest ages of 3 and 5 yr (Fig. 4a). SSB risk associated with maximum yield was rather high with both the proportional and threshold strategies, with the lowest first harvest age (47 and 36\%, respectively) but decreased as the first harvest age increased (Fig. 3b).

In all cases, the proportional threshold strategy performed best (Figs. 1c, 2c,f \& 4c). Maximum yield was highest from all 3 strategies at any given first harvest age (Fig. 3); moreover, varying asymptotic harvest fractions gave nearly equal mean annual yield. The CV of the yield in the proportional threshold strategy was the lowest of all 3 strategies independent of first harvest age (Fig. 2d-f). SSB risk remained relatively low irrespective of asymptotic harvest ratio or first harvest age, reaching a maximum of 0.2695 (SSB was below the threshold for $27 \%$ of the time series) with an asymptotic harvest ratio of 1 (all of the biomass above the threshold was removed) and with lowest first harvest age. It is noteworthy that the proportional threshold strategy is very robust to changing harvest ratio.

It is desirable that a harvesting strategy will provide a high maximum yield with low risk. In Fig. 3c, yield:risk ratios are plotted for all the strategies and different first harvest ages. Proportional threshold strategy was once again superior to the other 2 strategies. The threshold strategy performed 11 to $43 \%$ better (depending on the first harvest age) than the proportional strategy due to a lower SSB risk associated with it. The yield:risk ratio of the proportional threshold strategy was 50 to $60 \%$ higher than in the proportional strategy, and 30 to $55 \%$ higher than in the threshold harvesting strategy (Fig. 3c). When the precautionary strategies were included in the comparison (Fig. 5), there was no real difference in the maximum yields (expect for the difference between threshold and proportional threshold strategies). However, the SSB risk was up to $28 \%$ lower in precautionary threshold than in threshold harvesting, as well as at maximum $22 \%$ lower in precautionary proportional threshold than in proportional threshold harvesting (Fig. 5b). The yield:risk ratio was at most $28 \%$ higher in the precautionary threshold strategy than in the threshold strategy, and at maximum $20 \%$ higher in the precautionary proportional threshold than in the proportional threshold harvesting strategy (Fig. 5c). Explicit extinctions only occurred when the proportional harvesting strategy was implemented. Increasing the first harvest age decreased the probability of extinction, and when the first harvest age was high enough, the probability of extinction decreased to zero (Fig. 6a). Therefore, only proportional harvesting allowed calculation of the time to extinction. The time to extinction did, rather predictably, shorten with increasing harvest ratio and decreased with increasing first harvest age (Fig. 6b).

In the threshold strategy, short $(<10 \mathrm{yr})$ fisheries moratoria were very frequent, with a sharp decrease coupled with increasing first harvest age (Fig. 7a). In proportional threshold harvesting, the frequency of

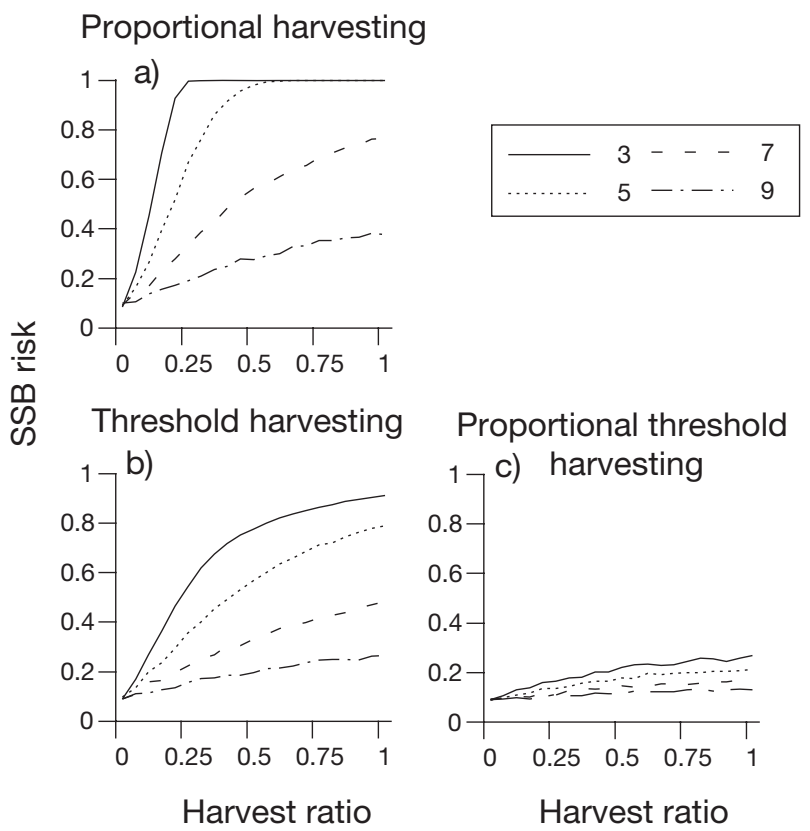

Fig. 4. SSB risk in (a) proportional, (b) threshold, and (c) proportional threshold harvesting strategies in relation to harvest ratio. Different lines indicate first harvest ages (yr) of Clupea harengus 

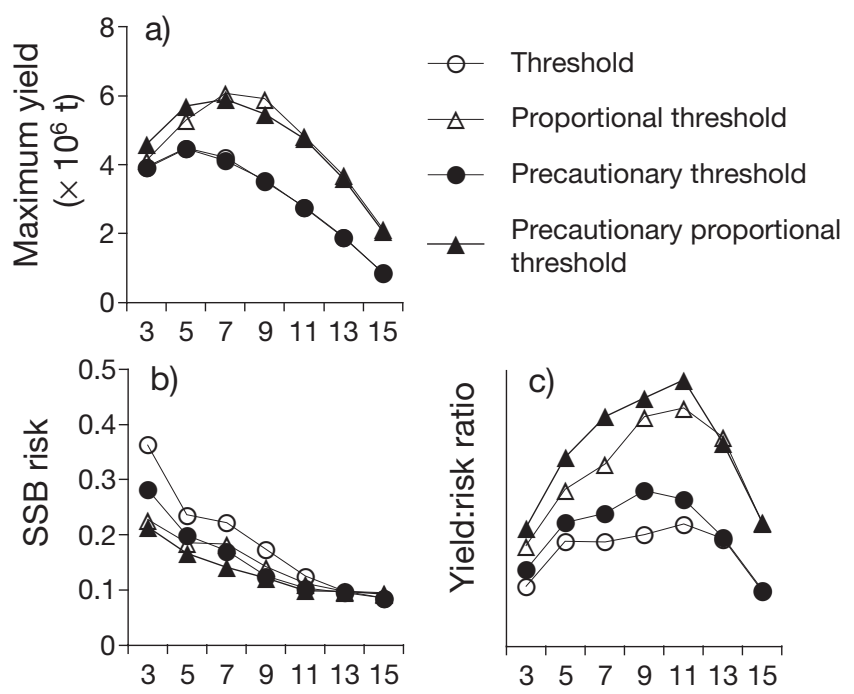

First harvest age

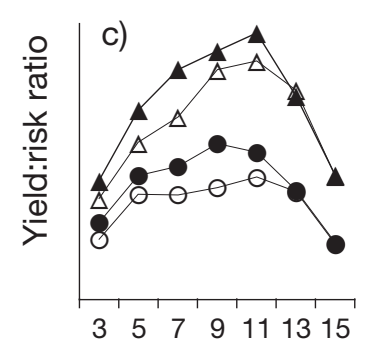

First harvest age

Fig. 5. (a) Maximum yield of Clupea harengus, (b) SSB risk corresponding to maximum yield, and (c) their ratio as a function of first harvest age (yr) in threshold, proportional threshold, precautionary threshold, and precautionary proportional threshold strategies

moratoria was much smaller, and the influence of increasing first harvest age was not as clear as in threshold harvesting (Fig. 7b).

In the threshold and precautionary threshold strategies with low first harvest ages there were many short moratoria, but as the first harvest age increased the average number of moratoria decreased, while the average length increased (Fig. 8a,b) Precautionary threshold harvesting produced fewer and shorter moratoria than threshold harvesting. In the proportional threshold strategy, the first harvest age affected neither the average number nor the average length of moratoria (Fig. 8a,b).

\section{DISCUSSION}

In my analysis of the adequacy of the 3 harvesting strategies - proportional, threshold, and proportional threshold harvesting - for the management of agestructured populations, the proportional threshold strategy appeared to be optimal in terms of mean annual SSB and yield, maximum yield, SSB risk, and the $\mathrm{CV}$ of the yield. The precautionary harvesting strategies developed in this study performed even better due to the 2-stage harvesting regime, especially when considering the length and the frequency of harvesting moratoria.

Comparing these results with those obtained using an unstructured model of the Norwegian spring

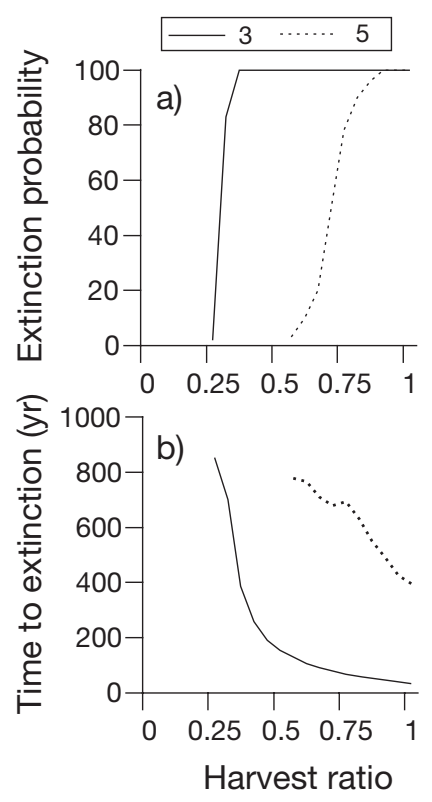

Fig. 6. (a) Extinction events in the proportional harvesting strategy and (b) the corresponding times to extinction as a function of harvest ratio. Different lines indicate first harvest age (yr) of Clupea harengus

spawning herring dynamics (Kaitala et al. 2003), it is obvious that adding age-structure has a significant effect on the predictions generated. In the unstructured model, none of the strategies (proportional, threshold, and proportional threshold harvesting) performed significantly better, whereas in this study the proportional threshold strategy outperformed the other 2 basic strategies. This is in concordance with the conclusions of several authors who have suggested using thresholds as means of sustainable harvesting (Lande et al. 1994, 1995, 1997, Sæther et al. 1996, Engen et al. 1997, Ludwig 1998).

Age-selective harvesting, which can be considered similar to size-selective harvesting (Halliday \& Pinhorn 2002), requires fishing gear allowing for such selectivity. Developing gear that would modify selectivity in a controlled manner has received attention in the last couple of decades (e.g. Robertson \& Ferro 1988, Robertson \& Stewart 1988, MacLennan 1992, 1995, Isaksen \& Valdemarsen 1994, Broadhurst 2000, Isaksen 2000). Consequently, increasing the first harvest age in the manner suggested in this study should not be impossible to implement in fisheries. In this study, the effects of age-selective harvesting were apparent in all the strategies with positive effects associated with increased first harvest age. This supports the general view that fisheries are targeting fish that are too young, thus preventing some of the population growth potential as a direct consequence (Kvamme \& Frøysa 2004). This can also be seen if we compare the model 


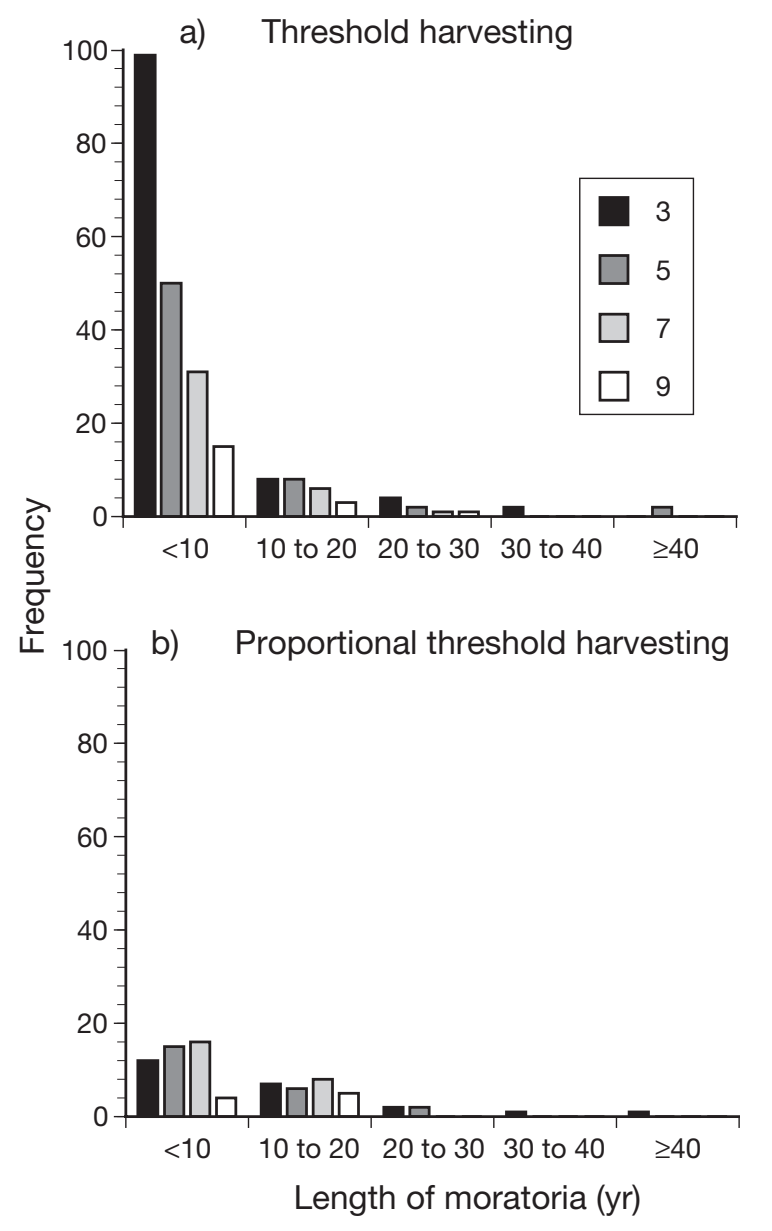

Fig. 7. Fisheries moratoria in (a) threshold, and (b) proportional threshold harvesting strategies. First harvest ages $(3,5$, 7, 9 yr) are shown

predictions in yield. In 1966, the yield peaked at $2 \times$ $10^{6} \mathrm{t}$ (Bjørndal et al. 2000); however, in this study it seems that there is potential for a much higher yield if the growth potential of the stock is adequately used. In the case of Norwegian spring spawning herring, selection based on size is meaningful until the fish are around $10 \mathrm{yr}$ old; after that, size does not correspond very well with age (Patterson 1998). However, in younger herring, there are substantial differences in size between age-classes (Patterson 1998); thus, selection ought to be possible.

The evolutionary effects of size-selective harvesting have caused some debate over the applicability of such management techniques based on size-selection (Jackson et al. 2001, Ratner \& Lande 2001, Conover \& Munch 2002, Stergiou 2002, Ernande et al. 2003). Sizeselective harvesting might in some cases lead to changes in the genetic structure of the stock, through favoring slow-growing, early-maturing fish. Such an undesired phenomenon could be avoided by introduc-
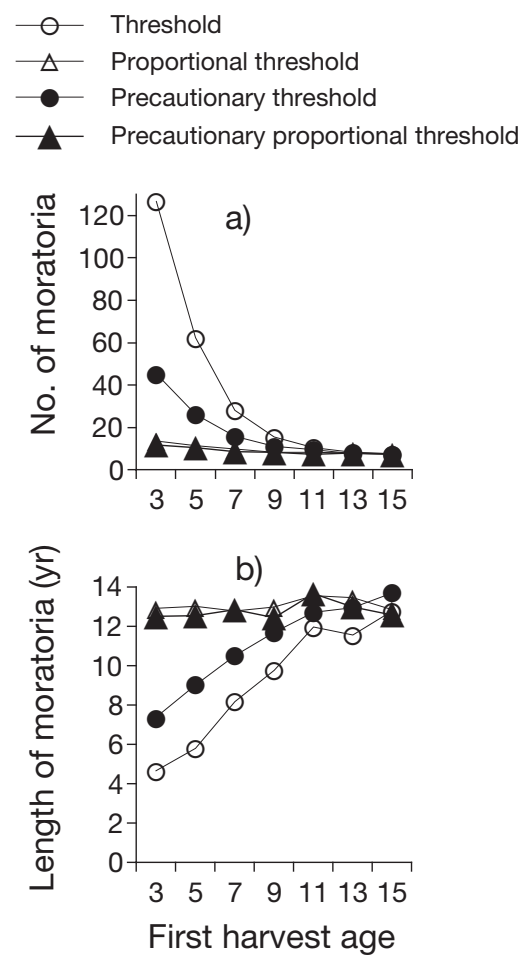

Fig. 8. (a) Mean number and (b) mean length of moratoria. The harvest ratio used was 0.2

ing maximum size limits (Conover \& Munch 2002). On the other hand, when within sustainable levels, some harvesting can increase the size of an individual via density-dependent somatic growth (Lorenzen \& Enberg 2002). In Norwegian spring spawning herring, following the stock collapse of the 1960s, fish matured earlier and, contrary to findings in some other stocks, at somewhat bigger sizes than before the collapse (Engelhard \& Heino 2004). A reason for this is found in growth-related phenotypic plasticity, rather than in an evolutionary response to harvesting (Engelhard \& Heino 2004). Thus, using size-selective harvesting strategies requires consideration of the possible evolutionary effects on the stock in question.

A major problem regarding threshold strategies, especially from the fisheries point of view, is their applicability. One may question whether it would be a feasible policy to close, for example, the Norwegian spring spawning herring fishery for a period of possibly even several decades. Even though this has happened in the case of Norwegian spring spawning herring (the fishery was closed in the 1960s and 1970s for a considerable time), from a sociological, political and economic point of view, it seems questionable that such actions would be taken repeatedly. However, precautionary strategies introduced in this study, in particular the precautionary threshold strategy, lessen 
the number and shorten the length of moratoria required. It is interesting that while increasing the first harvest age decreases the number of moratoria, it is associated with an increase in their length. As the likelihood of moratoria decreases with increasing first harvest age, the population may already be in a rather bad state if a moratorium is required; thus, recovery will take a longer time. In marine fish populations, from 90 populations studied for $5 \mathrm{yr}$ after a collapse, $41 \%$ continued to decline, $51 \%$ exhibited some recovery, and only $8 \%$ had fully recovered (Hutchings \& Reynolds 2004). Fifteen yr after the collapse, 12\% had fully recovered, whereas $40 \%$ had virtually not recovered at all. Therefore, developing harvesting strategies preventing such collapses is of major importance. Furthermore, as in my study where moratoria allowed no harvesting, in real fisheries systems, the harvest ratio might decrease $(\sim 52 \%$ of cases), remain relatively stable, or even increase $(\sim 30 \%$ of cases, Hutchings \& Reynolds 2004).

In conclusion, my results strongly support the use of harvesting thresholds in fisheries as a precautionary strategy. Moreover, shaping the catch selectivity such that it allows fish to reproduce more than once before becoming vulnerable to fisheries has an overwhelmingly positive influence on stock size, yield, risk of collapse, and the length and frequency of harvesting moratoria. A strategy allowing for decreased harvesting in times of declining population size, like in the precautionary strategies developed in this study, reduces the likelihood of population collapse. Consequently, the need for establishing moratoria diminishes, which in turn might have a positive socio-political impact. Overall, precautionary harvesting should produce an outcome desirable to all stakeholders.

Acknowledgements. I thank V. Kaitala for help in various stages of manuscript preparation, M. Fowler for language checking, and $\mathrm{M}$. Lindroos and 3 anonymous referees for critical comments on an earlier draft.

\section{LITERATURE CITED}

Arnott SA, Ruxton GD (2002) Sandeel recruitment in the North Sea: demographic, climatic and trophic effects. Mar Ecol Prog Ser 238:199-210

Beddington JR, May RM (1977) Harvesting populations in a randomly fluctuating environment. Science 197:463-465

Benton TG, Lapsley CT, Beckerman AP (2002) The population response to environmental noise: population size, variance and correlation in an experimental system. J Anim Ecol 71(2):320-332

Beverton RJH, Holt SJ (1993) Recruitment and egg-production. In: Beverton RJH, Holt SJ (eds) (1957) On the dynamics of exploited fish populations. Chapman \& Hall, London, p 44-67 (facsimile reprint 1993)

Bjørndal T, Hole AD, Slinde WM, Asche F (1997) Norwegian spring spawning herring - some biological and economic issues. Working paper 29, Foundation for Research in Economics and Business Administration (SNF), Bergen Bjørndal T, Kaitala V, Lindroos M, Munro G (2000) The management of high seas fisheries. Ann Oper Res 94:183-196

Broadhurst MK (2000) Modifications to reduce bycatch in prawn trawls: a review and framework for development. Rev Fish Biol Fish 10:27-60

Casey JM, Myers RA (1998) Near extinction of a large, widely distributed fish. Science 281:690-692

Conover DO, Munch SB (2002) Sustaining fisheries yields over evolutionary time scales. Science 297:94-96

Engelhard GH, Heino M (2004) Maturity changes in Norwegian spring-spawning herring Clupea harengus: compensatory or evolutionary responses? Mar Ecol Prog Ser 272: $245-256$

Engen S, Lande R, Sæther BE (1997) Harvesting strategies for fluctuating populations based on uncertain population estimates. J Theor Biol 186:201-212

Ernande B, Dieckmann U, Heino M (2003) Adaptive changes in harvested populations: plasticity and evolution of age at maturation. Proc R Soc Lond B Biol Sci 271:415-423

FAO Fisheries Department (2004) The state of world fisheries and aquaculture 2004. FAO, Rome

FAO Fishery Resource Division (1999) Indicators for sustainable development of marine capture fisheries. FAO Technical Guidelines for Responsible Fisheries No. 8, Rome

Halley JM (1996) Ecology, evolution and 1/f-noise. Trends Ecol Evol 11:33-37

Halley JM, Kunin W (1999) Extinction risk and the 1/f family of noise models. Theor Popul Biol 56:215-39

Halliday RG, Pinhorn AT (2002) A review of the scientific and technical bases for policies on the capture of small fish in North Atlantic groundfish fisheries. Fish Res 57:211-222

Heino M, Ripa J, Kaitala V (2000) Extinction risk under coloured environmental noise. Ecography 23(2):177-184

Hofmann EE, Powell TM (1998) Environmental variability effects on marine fisheries: four case histories. Ecol Appl 8:S23-S32

Hutchings JA, Reynolds JD (2004) Marine fish population collapses: consequences for recovery and extinction risk. BioScience 54:297-309

ICES (2003) Norwegian spring spawning herring sub-areas I and II. In: The stock book: annual review of fish stocks in 2003 with management advice for 2004. Fisheries Science Services, Marine Institute, Ireland. See also www.marine.ie/industry+services/fisheries/the+stock+book/ herring+norwegian+spring+spawners+ 03.pdf

Isaksen B (2000) The Norwegian procedure and experience concerning acceptance of new selective technology by the industry. FAO Fish Rep 588:S98-S105

Isaksen B, Valdemarsen JW (1994) Bycatch reduction in trawls utilizing behaviour differences. In: Fernö A, Olsen S (eds) Marine fish behaviour in capture and abundance estimation. Fishing news books, Blackwell Science, Oxford

Jablonski D (1986) Background and mass extinctions: the alternation of macroevolutionary regimes. Science 231: 129-133

Jackson JBC, Kirby MX, Berger WH, Bjorndal KA and 15 others (2001) Historical overfishing and the recent collapse of coastal ecosystems. Science 293:629-638

Kaitala V, Jonzen N, Enberg K (2003) Harvesting strategies in a fish stock dominated by low-frequency variability: the Norwegian spring spawning herring (Clupea harengus). Mar Resour Econ 18:263-274

Kvamme C, Frøysa KG (2004) Assessing the effects on stocks of selectivity changes in a fishery. Fish Res 69:283-292 Lande R, Engen S, Sæther BE (1994) Optimal harvesting, 
economic discounting and extinction risk in fluctuating populations. Nature 372:88-90

Lande R, Engen S, Sæther BE (1995) Optimal harvesting of fluctuating populations with a risk of extinction. Am Nat 145:728-745

Lande R, Sæther BE, Engen S (1997) Threshold harvesting for sustainability of fluctuating resources. Ecology 78(5): $1341-1350$

Loeng H, Bjørke H, Ottersen G (1995) Larval fish growth in the Barents Sea. In: Beamish RJ (ed) Climate change and northern fish populations. Canadian Special Publications of Fisheries and Aquatic Sciences 121, p 691-698

Lorenzen K, Enberg K (2002) Density-dependent growth as a key mechanism in the regulation of fish populations: evidence from among-population comparisons. Proc R Soc Lond B Biol Sci 269:49-54

Ludwig D (1998) Management of stocks that may collapse. Oikos 83:397-402

Ludwig D, Hilborn R, Walters C (1993) Uncertainty, resource exploitation and conservation: lessons from history. Science 260:17-18

Mace P (1994) Relationships between common biological reference points used as thresholds and targets of fisheries management strategies. Can J Fish Aquat Sci 51:110-122

MacLennan DA (1992) Fishing gear selectivity: an overview. Fish Res 13:201-204

MacLennan DA (1995) Gear selectivity and the variation of yield. ICES J Mar Sci 52:827-836

May RM (1974) Stability and complexity in model ecosystems, 2nd edn. Princeton University Press, Princeton, NJ

May RM, Beddington JR, Horwood JW, Shepherd JG (1978) Exploiting natural populations in an uncertain world. Math Biosci 42:219-252

Ottersen G, Loeng H (2000) Covariability in early growth and year-class strength of Barents Sea cod, haddock, and herring: the environmental link. ICES J Mar Sci 57:339-348

Patterson KR (1998) Biological modelling of the Norwegian spring-spawning herring stock. Report 1, Fisheries Research Services, Aberdeen

Pauly D, Christensen V, Guénette S, Pitcher TJ, Sumaila UR, Walters CJ, Watson R, Zeller D (2002) Toward sustainability in world fisheries. Nature 418:689-695

Editorial responsibility: Otto Kinne (Editor-in-Chief), Oldendorf/Luhe, Germany
Quinn TJ II, Fagen R, Zheng J (1990) Threshold management policies for exploited populations. Can J Fish Aquat Sci 47: 2016-2029

Ratner S, Lande R (2001) Demographic and evolutionary responses to selective harvesting in populations with discrete generations. Ecology 82:3093-3104

Ripa J, Lundberg P (1996) Noise colour and the risk of population extinctions. Proc R Soc Lond B Biol Sci 263: $1751-1753$

Robertson JHB, Ferro RST (1988) Mesh selection within the codend of trawls: the effect of narrowing the codend and shortening the extension. Scott Fish Res Rep 39. Dept of Agriculture and Fisheries for Scotland, Edinburgh

Robertson JHB, Stewart PAM (1988) A comparison of size selection of haddock and whiting by square and diamond mesh codends. J Cons Int Explor Mer 44:148-161

Rose GA, deYoung B, Kulka DW, Goddard SV, Fletcher GL (2000) Distribution shifts and overfishing the northern cod (Gadus morhua): a view from the ocean. Can J Fish Aquat Sci 57:644-663

Sæther BE, Engen S, Lande R (1996) Density-dependence and optimal harvesting of fluctuating populations. Oikos 76 : $40-46$

Sætre R, Toresen R, Anker-Nilssen T (2002) Factors affecting the recruitment variability of the Norwegian springspawning herring (Clupea harengus L.). ICES J Mar Sci 59:725-736

Sandberg P, Bogstad B, Røttingen I (1998) Bioeconomic advice on TAC - the state of the art in the Norwegian fishery management. Fish Res 37:259-274

Steele JH (1985) A comparison of terrestrial and marine ecological systems. Nature 313:355-358

Stergiou KI (2002) Overfishing, tropicalization of fish stocks, uncertainty and ecosystem management: resharpening Ockham's razor. Fish Res 55:1-9

Toresen R, Østvedt OJ (2000) Variation in abundance of Norwegian spring spawning herring (Clupea harengus, Clupeidae) throughout the 20th century and the influence of climatic fluctuations. Fish Fish 1(3):231-256

Touzeau S, Kaitala V, Lindroos M, Ylikarjula J (2000) Economic and biological risk analysis of the Norwegian springspawning herring fishery. Ann Oper Res 94:197-217

Submitted: December 28, 2004; Accepted: June 2, 2005

Proofs received from author(s): July 29, 2005 